\title{
A Comparison Study about the Public Perception on Neuroscience in China and Japan
}

\author{
Yisi Yang \\ Shanghai, China \\ Email: yangyisi@fuji.waseda.jp
}

How to cite this paper: Yang, Y.S. (2018) A Comparison Study about the Public Perception on Neuroscience in China and Japan. Open Journal of Social Sciences, 6, 85-107.

https://doi.org/10.4236/jss.2018.611006

Received: October 10, 2018

Accepted: November 9, 2018

Published: November 12, 2018

Copyright $\odot 2018$ by author and Scientific Research Publishing Inc. This work is licensed under the Creative Commons Attribution International License (CC BY 4.0).

http://creativecommons.org/licenses/by/4.0/

\section{cc) (i) Open Access}

\begin{abstract}
This dissertation attempts to describe the ways in which neuroscience is perceived by the public in China and Japan from media and individual perspectives. This research adopts triangulation methods, including the empirical data from literatures, media content analyses of newspapers, and two focus groups in China and Japan. Both content analyses and focus groups are guided by the literature review. The central findings are that there are some distinctions of the public perception of neuroscience between China and Japan. On the media perspective, Chinese and Japanese media have different concentrations on neuroscience communication. Meanwhile, on the individual perspective, the participants from China and Japan also present different understanding and attitudes to neuroscience, which further confirms the results of content analyses.
\end{abstract}

\section{Keywords}

Neuroscience, Content Analysis, Focus Group, Public Perception

\section{Introduction}

Neuroscience is closely related to our life. With the emergency of neuroscientific technology such as fMRI, there is a growing awareness of neuroscience among the public. However, there have been few studies on the relationship of the public and neuroscience in Eastern countries, compared with the relatively complete neuroscience communication researches in Western context.

There are two perspectives used within this study to understand the perception of neuroscience, the media and the public. This dissertation attempts to describe and identify how neuroscience is represented in Chinese and Japanese mainstream media and the understanding of individuals of the new technologies in the field. The purpose of this is to explore and delineate the differences of and 
the reasons behind the neuroscience understanding between the two cultural contexts. The central findings are that the media coverage and the individual understanding of neuroscience are different between China and Japan.

The current study attempts to identify the cultural uniqueness of groups and identify the individual ideas of each of the focused groups regarding neuroscience. The implication of this dissertation is to provide suggestions for the process of spreading neuroscience information to the public. Specifically, these main differences in the communicative content can be presented as: 1) the Chinese public perception of neuroscience pays more attention to the neuroscientific information in the field of medicine and health; 2) the Japanese public perception prefers the neuroscientific knowledge related to economic value and daily life. In terms of communicative forms, the difference is that: 3) Chinese individuals distrust the neuroscience reports released by the government; 4) there is an information gap between Japanese individuals and scientists. This research tries to explain the reasons for these differences and provide the future suggestions based on the social psychology theory.

\section{Research Questions}

\section{The research questions:}

What are the public perceptions of neuroscience within Chinese and Japanese cultural contexts?

\section{The sub-research questions will be:}

1) What is the media perception of neuroscience in Chinese and Japanese cultural context?

2) What is the Chinese public's perception of neuroscience based on the media information?

3) What is the Japanese public's perception of neuroscience based on the media information?

4) What are the differences between the two cultural groups?

\section{Literature Review}

\subsection{Introduction}

The key purpose of this research is to identify the perception of the Chinese and Japanese public on neuroscience in their own cultural background. However, there are few Chinese and Japanese literatures referring to the media study of neuroscience. Therefore, in this chapter, the origin and development of media representation of neuroscience will be presented based on Western research. The second part of this chapter will outline the background literature regarding Chinese and Japanese science communication studies which will lay the foundation for understanding public perception of scientific media information. This part will be made up of two section including literature regarding media representation studies of neuroscience, research on fundamental science communicative studies in the East Asian context. 


\subsection{The Origin and Development of Western Media Studies of Neuroscience}

\subsubsection{The Beginning of the Public Understand of Neuroscience}

Early research on neuroscientific issues can be traced back to 1980s. Changeux (1983) [1] redefined the relationship between humanities and neuroscience and called for a renewal of philosophy and the humanities (Changeux, 1983). Then, Churchland (1989) [2] put forward the philosophical interpretation of 'neuroscience' with the foundation of her neuroscience survey.

\subsubsection{The Developing Research Stage of Neuroscience}

The public perception of neuroscience has a close relationship with technological development. Based on the support of technologies such as fMRI (Young \& Saxe, 2008) [3] and deep brain stimulation (DBS) (Deep Brain Stimulation), Eric, Sarah, Jarett and Judy (2010) [4] conducted a small-scale research of neuroscience focused on the print media. In the light of the various technologies, the description of "neuroscience" in this report highlighted the importance of the function of media forms and pointed out there was an information gap between neuroscientific knowledge and society. In other words, the neuroscience field faces unavoidable challenges during the communicative process necessary to achieve public understanding. In addition, in "fMRI in the Public Eye" Eric, Ofek and Judy (2006) [5], raised ethical arguments of neuroscience technologies, highlighting how the sophistication of Fmri makes it difficult for the public to comprehend every detail of neuroscientific areas, especially leading to technical deficiencies in understanding.

In addition to the neuroscience media research based on technical classifications, there has been a trend of news article studies being written on topics such as health, the law, and politics. In the research conducted by van Atteveldt et al. (2014) [6] concluded the timing of newspaper publishes, the different topics of neuroscience, and the newspaper forms such as a special column and a press release, in would influence the media attitude of neuroscience.

Rather than analyze the relationship between the available technologies, such as fMRI, PET, and EEG, and neuroscience, Scott (2010) [7] explored the media reports of the neuroscience from the perspectives of power and culture. Compared to Racine et al.'s (2006) [5] research on media studies of neuroscientific knowledge, Scott laid more emphasis on social and political explanations. Furthermore, in supplement to the content analysis of the print media conducted by Racine et al. which was classified by neuroscientific technologies, Grabowski (2014) [8] published a book about the media representation of neuroscience which included more kinds of media forms such as offline and online transmission. In this study, Grabowski analysed a great deal of digital age neuroscience media communication based on cultural and social theories.

\subsubsection{Controversies in Media Coverage of Neuroscience}

1) Philosophical Explanations

Churchland (1989) [2] mentioned the duality of the brain and mind when ex- 
plaining neuroscience from the perspective of philosophy, laying the foundation of the neuro-philosophical debate. Volney (2009) [9] explored the philosophical relationship between neuroscience and religion such as the debate on whether human being is equal to a super computer. Slingerland (2008) [10] used reductionism (Putnam, 1973) [11] to explain neuroscience, which means that comprehend the nature of neuroscience by segmentation fields such as brain activities. Also there was another interpretive style called humanism (Slingerland, 2008) [10] which implied that comprehending human being and society ass whole. The former one concentrated on the physical comprehension of neuroscience and the latter one aimed at human-level. However, there were controversies between reductionalistic and humanistic interpretations, leading to the author introducing the concept of dual consciousness to understand the neuroscience issues.

In addition, Racine and his research group (2005) [12] referred to the discussion between "neuro-essentialism" and "neuro-realism" in the media coverage of the neuroscience as the main tendencies of reporting on new neuro-technologies, alongside neuro-policy. Neuro-essentialism preferred to define the brain as an independent and initiative subject equal to the soul (Racine et al., 2005) [12], while neuro-realism regarded the brain as an object which could be represented by the scientific data. Also the third explanation way of neuroscience information is neuro-policy, which placed emphasis on introduction of neruoscentific influence and implication. Each method of conveying the neuroscientific information to the public is affected the media workers' understandings of the neuroscience, meaning the media cannot convey the entirety of the information necessary.

2) Challenges in Communication of Neuroscience

In addition to the controversial nature of the explanations of brain science, there is a generational information gap between media reports and new neuroscientific knowledge. Holman (2011) [13] discussed the problems of contemporary neuroscience information in the media, with a focus on newspapers, in which the use of neuroscience in a very general sense grossly oversimplifies complex phenomena was the key issue highlighted. As reported by Giridhard as (2008) [14], the usage of the brain scanning in the legal field is widely doubted, and a decision of the Indian police to use brain scanning technology to declare a suspect guilty caused great social discussion.

Strokes (2013) [15] argued there is a misinterpretation of neuroscience news reports, referring to two main principles in communicating neuroscience information. Firstly, the brain and the mind were associated, and the inability to simply adopt physical data to indicate the neuroscience as the brain is not isolated. Furthermore, van Atteveldt et al. (2014) [6] stated the media representation of neuroscience would be affected by the external factors. For example, it would be more positive when reporting on the development of neuroscience, however would show more skeptical attitude to the legal applications and regulations of neuroscientific techniques. 
In conclusion, the role of the media is critical during the communication of neuroscience. This is because, as Beck (2010) [16] remarked, the bias of the media coverage of neuroscience has the potential to misguide the public. Hence, media reports of neuroscience should remain objective, and, when dealing with neuroscience data, mis-and over-interpretation of the field should be avoided by the press and scientists. The problems with the media's depiction of neuroscience runs the complete range from citing researches incorrectly, achieving grand, false conclusions from misinterpreted data, and appropriating neuroscience in the name of explaining phenomena beyond the field's immediate purview.

\subsection{Public Understanding of Science in China and Japan}

Chinese and Japanese media studies on neuroscience are not as complete as in the Western cultural context. However, research about scientific communicative systems provides a solid foundation for the current research. Vitally, different groups of people from different countries have varying understanding of new science. Therefore, this dissertation aims to set up a coherent framework using a combination of theoretical systemic research of neuroscience media reporting in the Western cultural contexts and general science communicative studies in Chinese and Japanese cultural contexts.

\subsubsection{Comparison Studies of Science Communication between Countries} Notably, comparative studies between different countries regarding societal and public perceptions of science communication are focused on specific and more popular scientific areas such as vaccinations and artificial intelligence (AI). According to Lan's (2009) [17] investigation of the public opinion of biotechnology in China and Europe, different countries have their own preferences for new science. For instance, the Chinese pay more attention to the usefulness and applications of biotechnologies while Europeans were more likely to concentrate on understanding the technical risks. When it comes to highly controversial scientific issues, the study on media coverage of research on vaccinations by Ren et al. (2014) [18] found Chinese media information had differing features than UK media reporting. To be more specific, the Chinese government had a deeper impact on science reports and more expert testimony was than in the UK media.

In addition, media and public surveys within Western and Eastern countries about science communication reflected social, political, and cultural issues. In the book written by Raza et al. (2011) [19] about the comparison of science communication development between China and India, various factors which led to the scientific differences between two countries were explored, tracing back to the 1980s. In particular these were related to the colonial influence and multiple national languages, which meant science communication in India, had not developed a national literacy. However, although China's scientific communication developed quickly, there is an information gap between the Chinese public and science knowledge. 
In 2002, the Japanese National Institute of Science and Technology Policy (NISTEP) had launched the survey about the public perceptions of the science. (Kawamoto et al., 2013) [20] Also, Kawamotoand his research group designed a large-scale investigation which aimed at the participants who were over 18 years old. This quantitative study was made up of three elements and four categories. They teased out the each connection between each factor such as the science appreciating factor has high and positive relationship with the social factor. Based on these findings, this group compared to the UK general scientific literacy reports to explore the differences.

\subsubsection{The Chinese Government's Domination of Science Communication} The current situation of scientific transmission in China is, therefore, not optimistic, especially due to the influence of the government which manifests in an over-politicization of science (Zhang, 2015) [21] and a one-way communication of the science information (Liu, 2014) [22]. Due to the cultural evolution policy ${ }^{1}$ (1966-1976) which almost destroyed the Chinese science communication system, the Chinese government started to set up a scientific communication system in 2002 (China State Council, 2002), which was primarily aimed at informing the public of scientific results rather than its progress. Therefore, utilitarianism is a problem in Chinese science communication (Liu, 2014) [22], with it being delivered through a kind of top-down transmission.

While, in general, the Chinese science communication is developing rapidly, the problems caused in the scientific system by governmental and political factors, have become barriers to science communication. Specifically, the information given to the Chinese public is represented by the government, causing people's resistance to the political power. This is the main reason why Chinese people have credibility crisis of the science information in the media coverage especially the newspaper (Zhang, 2015) [21]. Therefore, on the grounds of the general media research of science communication, this research attempts to lay emphasis on the specific neurological realm of science to identify the understanding and perceptions of the Chinese society about the field.

\subsubsection{The Restricted Science Communication among Japanese Scientists} Japanese scientific communication studies show a lack of communicative consciousness is one of the most important problems for the Japanese society. In 2013, there was a report about the science communication conducted by the Japanese government. It was amazing to see that only $64 \%$ of the scientists under investigation had been communicated with the external communities such as the public, the academic seminar, the media agency (Koizumi et al., 2013) [23]. In an article published by Koizumi et al. (2013) about the situation amongst Japanese scientists, over half of the interviewees (scientists) had no interactive communication with the public. Therefore, the research group provided four sugges-

${ }^{1}$ The Cultural Revolution, formally the Great Proletarian Cultural Revolution, was a sociopolitical movement that took place in China from 1966 until 1976. The movement negatively affected the country's economy and society. 
tions to change this situation, including policies of encouragement policies. Moreover, Kornhauser (2015) [24] talked about the problem of Japanese science communication, claiming it was the cause of a lack of institutions and professionals, and the media workers who reported on science information lack enough professional training. Hence, these factors cause an information gap between the Japanese public and the science media.

\subsection{Conclusion}

Overall, both the Chinese and Japanese are currently lacking in their science communication research, though there are movements to develop and improve this. While the majority of the research mentioned above only looks at general science communication studies, the basis of this dissertation is the theoretical foundation of science communication. With the high development of neuroscience and AI, it is worth identifying public attitudes towards these new technologies as they become more of a part of public life.

In addition, scientific and educational information has a close relationship with the mass media, as identified in Bauer et al.'s (2001) [25] study which explored the media representation of biotechnology in the light of different countries. They raised the concept of dramatization which means analyzed the media coverage of biotechnology according to the classic drama theoryto explain media studies of science communication and in doing so provided another perspective to analyze the science transmission to the public. Then they found that when readers (audience) reached the biotechnological information, their emotions were guided by the special passion prepared by the drama (biotechnological disseminator). Therefore, this dissertation plans to explore and explain the media representation of neuroscience from several perspectives including the media, the public, and scientists.

\section{Methodology}

\subsection{Introduction}

The main purpose of this research is to study the public perception of the neuroscience in China and Japan and explore the differences between the two countries. Therefore, this study plans to employ a mixed methodological method (both quantitative and qualitative) which includes the triangulation of various sources of information including two small-scale media content analyses of the mainstream newspapers and two focus groups. Firstly, the media content research offers basic media reports on neuroscience. Then, based on the media content analysis, the focus groups will reflect the ideas of individuals on new neuroscientific knowledge and support discussion one reasons for the differences in perceptions. Furthermore, this dissertation gained informational support from the related literature from the Western context and fundamental research on Chinese and Japanese science communication.

The first part of this chapter will begin with discussion about the necessity of 
choosing media content analysis as the key method of this dissertation. The sampling section will indicate the process of corpus construction. Then this chapter will move on to the focus group discussions used for the further analysis of neuroscientific communication.

\subsection{Content Analysis}

\subsubsection{Dynamic Comparison}

As Runyard and French (1999) [26] said, the beginning of research should focus on the media. This is because the media represents a society's attitude to specific issues. Because of this and the research questions of this dissertation, specifically the aim to explore the general understanding of neuroscience and find the differences of these attitudes between the two countries in question, content analysis of the media articles is suitable. This is because it is a method for the objective, systematic, and quantitative description of the manifested content of communication (Berelson, 1952) [27].

Media content analysis is a research strategy which covers different times and spaces (Bauer \& Gaskell, 2000) [28]. Specifically, content analysis can be used for the horizontal comparison among different periods in one country. Vitally, the contrast between China and Japan can be presented by content analysis. As such, this facilitates a dynamic comparison which will play a key role in this research on public perception, allowing exploration of issues across a long period to present a more accurate and convincing conclusion. This is convenient in finding the specific changes within the public understanding of neuroscience and the differences between China and Japan.

\subsubsection{Objective and Narrative Analyzing Principles}

Another reason for this dissertation to choose content analysis is because of its high degree of objectivity (Krippendorff, 2004) [29], which a general perception of neuroscience in society should be. As Bauer (Bauer \& Gaskell, 2000) [28] said, content analysis is the bridge between the qualitative content and quantitative data as it turns qualitative materials into standardized codes. Moreover, a feature of media content analysis "noninvolvement" (Chen, 2007) [30] is an important factor in the choice of this method as it means there is no need for researchers to conduct a field investigation. In addition, the materials of media content analysis can be investigated more than one time. Overall, the research processes of media content analysis are able to guarantee objective and accurate findings.

Most newspapers articles include multiple topics (Tennant, 2012) [31], and the topics which will need to be analyzed in this dissertation are include medical, military, and AI narrative media coverage. Moreover, this research will visualize its results by the frequency of codes, as identifying the co-occurrence of words within the same sentence or paragraph demonstrates relevant meanings (Bauer\& Gaskell, 1999) [32]. As a result, this research attempts to identify media coverage on neuroscientific differences between China and Japan through the frequency of key concepts which appear in the selected articles. 


\subsection{Corpus Construction and Sampling-Stratified Sampling}

The main source for this dissertation is Chinese and the Japanese mainstream newspapers. For both countries, the newspaper is the main media form by which the public is informed about the developments in and situation of new science. In other words, the main way for the Chinese and Japanese people to obtain information on science and technology is reading newspaper, be they online or in print.

A key word research of the top three news portals (Renmin, Xinhua, and Sina) in China and Japan (Asahi Shimbun, Nikkei Shimbunnews paper, and 2 Channel News Navigator) from inception in 201322 July 2013 to 22 July 2017 for all articles that which include the index terms "brain", "mind", or "soul" creates a corpus of 6000 articles. Among these articles, 2989 of them are from the Chinese context and 3000 are from the Japanese context. According to the principlestratification of the sample choosing (Krippendorff, 2004) [29], the sampling is based on the different proportions of the periods. The first step of the sampling is to organize all the Chinese newspaper articles together, then ordering them. Then in the light of the chronologically order, these news articles are renumbered. After this, the random sampling method is adopted to extract a sample article from every 50 articles to arrange the Chinese corpus. The same process is carried out on the Also the Japanese corpus is made by taking the same sampling methods in the Japanese context. Therefore, to gain This leaves a total corpus of 120 articles (60 from China and 60 from Japan) the to analyze the basic media representations of neuroscience from the two countries, specifically within the period of, the corpus to be analyzed is made up with 120 newspaper articles (100 from China and 100 from Japan) which appeared on the mainstream news office from 2013 to 2017. Table 1 and Table 2 indicate the numbers of articles present in both the Chinese and Japanese corpus and the collected sample which will be analyzed in this research. Also the comparison of the number of the newspaper reports including "neuroscience" or "mind" or "soul" between China and Japan can be seen in Figure 1.

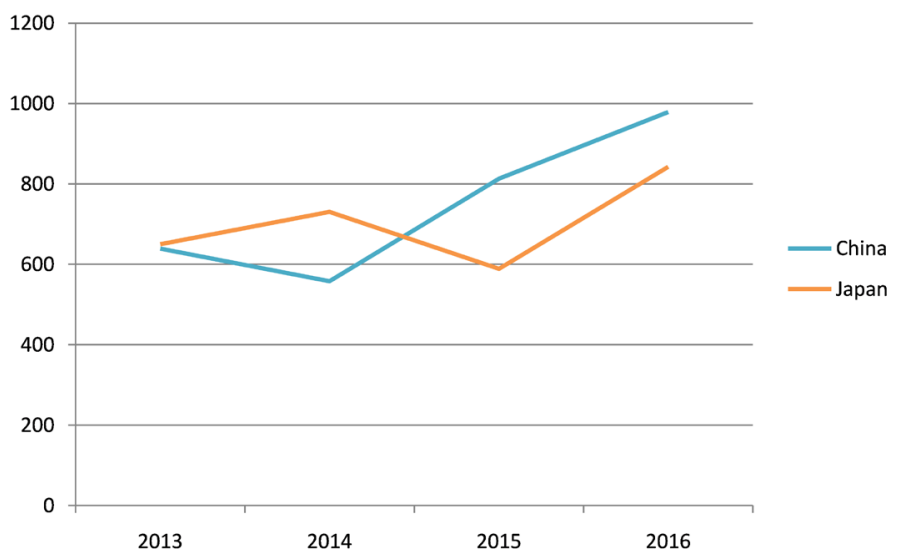

Figure 1. Number of the newspaper reports including "neuroscience" or "mind" or "soul" in China and Japan. 
Table 1. Number of articles in corpus and sample (Underlined is the largest number; Bold is the least number).

\begin{tabular}{ccccccccccc}
\hline & \multicolumn{1}{c}{ Number of articles in corpus and sample in Chinese } \\
\hline & \multicolumn{9}{c}{ Total } & \multicolumn{5}{c}{ Sample } \\
\cline { 2 - 9 } & $2013-2014$ & $2014-2015$ & $2015-2016$ & $2016-2017$ & Total & $2013-2014$ & $2014-2015$ & $2015-2016$ & $2016-2017$ \\
Newspaper Title & 639 & 558 & 813 & $\underline{979}$ & 2989 & 13 & 12 & 16 & $\underline{19}$ & 60 \\
Renmin $^{2}$ & 214 & 227 & 290 & 332 & $\underline{1063}$ & 5 & 5 & 5 & 7 & $\underline{22}$ \\
Xinhua $^{3}$ & 187 & 198 & 208 & 393 & 986 & 4 & 3 & 4 & 8 & 20 \\
Sina $^{4}$ & 238 & 133 & 315 & 254 & 940 & 5 & 3 & 6 & 5 & 19 \\
& 639 & 558 & 813 & 979 & 2989 & 14 & 11 & 15 & 20 & 60 \\
\hline
\end{tabular}

Table 2. Number of articles in corpus and sample (Underlined is the largest number; Bold is the least number).

\begin{tabular}{|c|c|c|c|c|c|c|c|c|c|c|}
\hline \multicolumn{11}{|c|}{ Number of articles in corpus and sample in Japanese } \\
\hline & \multicolumn{5}{|c|}{ Total } & \multicolumn{4}{|c|}{ Sample } & \multirow{2}{*}{ Total } \\
\hline & 2013-2014 & 2014-2015 & 2015-2016 & 2016-2017 & Total & 2013-2014 & 2014-2015 & 2015-2016 & 2016-2017 & \\
\hline Newspaper Title & 650 & 731 & 589 & $\underline{843}$ & 2813 & 15 & 16 & 12 & $\underline{17}$ & 60 \\
\hline Asahi Shimbun ${ }^{5}$ & 275 & 400 & 266 & 344 & $\underline{1285}$ & 6 & 9 & 5 & 7 & $\underline{27}$ \\
\hline Nikkei newspaper ${ }^{6}$ & 239 & 198 & 145 & 315 & 897 & 5 & 3 & 3 & 7 & 18 \\
\hline \multirow[t]{2}{*}{$\begin{array}{l}2 \text { Channel News } \\
\text { Navigator }^{7}\end{array}$} & 166 & 133 & 178 & 184 & 661 & 4 & 2 & 4 & 4 & 14 \\
\hline & 650 & 731 & 589 & 843 & 2813 & 15 & 16 & 12 & 17 & 60 \\
\hline
\end{tabular}

\subsection{Coding Framework}

The final coding framework was made up of a total of 26 variables chosen after analyzing the newspaper materials.

First of all, each newspaper article is numbered by a unique code ( $01-60$ for Chinese newspapers; 61 - 120 for Japanese newspapers) and each is analyzed as an independent unit. The first 30 articles from the Chinese corpus and the first 30 articles from the Japanese corpus are used to set up the themes and the variables. Then these steps are then repeated for the next 10 articles until the saturation of the variables have been achieved.

All articles in the two corpuses are narrative coverage of neuroscience information. Among these articles, there are 30 variables belonging to five themes: two related to the nature of the brain or mind (including what they are and what they do), "philosophical or existential implications", "sociological implications", and "practical implications", which can be seen in Table 3.

The first component of code is about the basic information of these articles (N1 - N4) and includes the unique number, the publication outlet, the date of publication, the quotation information (be they scientists, physicians, patients

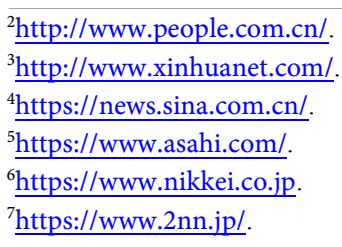


and their family members, journalists, politicians or, representatives from a private company) (Racine et al., 2010) (Table 4). Other variables are recoded in the same order (N5 - N30). The newspaper materials in the two corpuses were coded systematically in a binary manner, where each article, per variable, was given either a " 1 ", meaning the article could be categorized as said variable, or a " 0 ",

Table 3. The themes and the variables.

\begin{tabular}{|c|c|}
\hline Themes & Coders \\
\hline \multirow{7}{*}{$\begin{array}{l}\text { What the brain } \\
\text { and mind are }\end{array}$} & Brain tumour \\
\hline & Cerebral injury \\
\hline & Encephala trophy \\
\hline & Cerebral apoplexy \\
\hline & Brain health care \\
\hline & Traditional Chinese medicine \\
\hline & Brain death \\
\hline \multirow{4}{*}{$\begin{array}{l}\text { What the brain } \\
\text { and mind do }\end{array}$} & Brain wave research \\
\hline & Near-death experience \\
\hline & Animal brain research \\
\hline & Brain scans (i.e. $\mathrm{fMRI}$ ) \\
\hline \multirow{5}{*}{$\begin{array}{l}\text { Philosophical or } \\
\text { existential implications }\end{array}$} & Self-consciousness based on the brain activities \\
\hline & Doubt about consciousness after death \\
\hline & Doubt about the soul \\
\hline & Subjective experience (i.e. out of body experiences) \\
\hline & Discussion about the afterlife world \\
\hline \multirow{6}{*}{$\begin{array}{l}\text { Sociological } \\
\text { implications }\end{array}$} & AI \\
\hline & Smart home (i.e. Intelligent home system) \\
\hline & Military \\
\hline & Driverless car \\
\hline & New media (i.e. virtual reality) \\
\hline & Medical care \\
\hline \multirow{3}{*}{ Practical implications } & Improvement of first aid \\
\hline & Efficiency improvement (i.e. the disabled) \\
\hline & Sleeping insurance (i.e. the sleeping time of night shift workers) \\
\hline
\end{tabular}

Suggested by advisor Chris Tennant.

Table 4. The basic information of the media samples.

\begin{tabular}{|c|c|c|c|}
\hline \multirow{7}{*}{ No. } & \multirow{7}{*}{$\begin{array}{l}\text { Publishing } \\
\text { agency }\end{array}$} & \multirow{7}{*}{$\begin{array}{c}\text { Date of } \\
\text { publication }\end{array}$} & Quoting information \\
\hline & & & 1) Scientists with the university support \\
\hline & & & 2) Patients and family members \\
\hline & & & 3) Physicians and other medical workers \\
\hline & & & 4) Business representatives \\
\hline & & & 5) Staff from government \\
\hline & & & 6) Athletes \\
\hline 01 & Renmin & 20130803 & 5 (For example) \\
\hline
\end{tabular}


meaning it could not.

\subsection{Focus Groups}

The disadvantage of content analysis is that the results it provides are mostly collective-level data. This study will attempt to make up for this by using focus groups, an inter-personal level method which allows a study to find out individual opinions through discussion and sharing understanding within group work. There are two important parts of focus groups, the recording of the insight of the participants and the interaction among the participants during the focus group.

Due to the aim of this dissertation being to compare differences in public perception, it is important to gain public opinion on the topic, meaning the discussion process and deep data collection are necessary. Specifically, the insight of individuals on neuroscientific information can be used as a representation of public attitudes.

The key purpose of the two focus groups was to have the participants discuss the following:

- Their impressions of neuroscience such as brain activity and brain scans across the five themes identified in the coding

- The differences of newspapers reporting on neuroscience between China and Japan;

- The kind of neuroscience newspaper reporting the participants want to see.

\section{Findings}

\subsection{Media Content Analysis}

\section{Results of Media Content Analysis}

1) Basic Information Analysis

In this research, 120 articles featuring neuroscience from 2012 to 2017 were identified. Among these articles, 60 originated from China and 60 are from Japan.

In the Chinese sample, $68.6 \%$ of Chinese newspaper articles in the sample are the publications with official support such as Renmin newspaper ${ }^{8}$ and Xinhua ${ }^{9}$, which both have a close relationship with the government. From the Japanese sample, the biggest newspaper agency, the Asahi Shimbun ${ }^{10}$, is a private enterprise which supports the left-wing party, an operation mode also followed by the Nikkei Shinbun.

It can be seen in the Table 5 that almost 33\% of newspaper articles in the total sample used the quotations from the scientists $(\mathrm{N}=120)$. The second-mostcited source, at around $25 \%$, is the opinions of the physicians and other medical workers. The third-most is information from patients and their family members in newspaper reports, which accounts for twenty percent of cited sources.

${ }^{8}$ Renmin newspaper is the biggest newspaper group in China. The paper is an official newspaper of the Chinese Communist Party.

${ }^{9} \mathrm{Xinhua}$ is the biggest and most influential media organizationin China and a ministry-level institution subordinate to the Chinese central government.

${ }^{10}$ Asahi Shinbun is the biggest Japanese newspaper, headquartered in Osaka. 
Table 5. Sources of quotation for articles about neuroscience (Underlined is the largest number; Bold is the least number).

\begin{tabular}{ccccccc}
\hline $\begin{array}{c}\text { Sources of } \\
\text { quotation }\end{array}$ & $\begin{array}{c}\text { China } \\
\text { Frequency } \\
\text { of Coders }\end{array}$ & $\begin{array}{c}\text { Total } \\
\text { Percentage } \\
\%\end{array}$ & $\begin{array}{c}\text { Japan } \\
\text { Frequency } \\
\text { of Coders }\end{array}$ & $\begin{array}{c}\text { Total } \\
\text { Percentage } \\
\%\end{array}$ & $\begin{array}{c}\text { Total } \\
\text { Frequency } \\
\text { of coders }\end{array}$ & $\begin{array}{c}\text { Total } \\
\text { Percentage } \\
\%\end{array}$ \\
\hline $\begin{array}{c}\text { Scientists with the } \\
\text { university support }\end{array}$ & 14 & 23.3 & $\underline{32}$ & 53.3 & $\underline{46}$ & $\underline{38.3}$ \\
$\begin{array}{c}\text { Physicians and other } \\
\text { medical workers }\end{array}$ & $\underline{20}$ & 33.3 & 10 & 16.7 & 30 & 25.0 \\
$\begin{array}{c}\text { Patients and family } \\
\text { members }\end{array}$ & 18 & 30.0 & 6 & 10.0 & 24 & 20.0 \\
$\begin{array}{c}\text { Business } \\
\text { representatives }\end{array}$ & 6 & 10.0 & 8 & 13.3 & 14 & 11.7 \\
$\begin{array}{c}\text { Staff from } \\
\text { government }\end{array}$ & 2 & 6.7 & $\mathbf{2}$ & 3.3 & 4 & 3.3 \\
Athletes & $\mathbf{0}$ & 0 & $\mathbf{2}$ & 3.3 & $\mathbf{2}$ & $\mathbf{1 . 6}$ \\
\hline
\end{tabular}

The least cited sources overall are business representatives, government staff, and athletes. Specifically, in the Chinese sample, quotations from physicians, scientists, and patients were the most mentioned in the newspaper articles, while in the Japanese articles, scientists with university support were quoted most frequently, taking up just over $53 \%$, followed by hospital physicians and business representatives respectively.

2) Newspaper Content Analysis

Around 220 articles (25.4\%) of the total sample reported on "What the brain and mind are", which involves topics such as brain tumors, cerebral injuries, encephala trophy, and brain healthcare? (Table 3) The most frequently mentioned codes were cerebral injury (26.1\%), such as the permanent loss of brain cells, brain health care (23.4\%), such as the protection of blood vessels in brains, and cerebral apoplexy (20.7\%), such as intra-cerebral hemorrhages and ischemic strokes.

To give more detail, in the Chinese newspapers, cerebral injury was the most frequent code, accounting for $23.1 \%$, followed by the frequency of encephala trophy, cerebral apoplexy, and brain healthcare $(22.0 \%)$ as a virtual tie for second place. However, the information about brain tumors (1.1\%), traditional Chinese medicine $(2.2 \%)$, and brain death (7.7\%) were the least mentioned in Chinese newspapers on neuroscience. Moreover, within the Japanese samples, the most frequently cited code was cerebral injury (40.0\%), followed by brain healthcare (30.0\%) and cerebral apoplexy (15.0\%). However, the Japanese articles did not refer to brain tumors or traditional Chinese medicine. Overall, in the first theme of the discussion on what the brain and mind are, Chinese newspapers prefer to lay more emphasis on specific brain diseases and brain health problems than the Japanese articles.

In the second identified theme 'What the brain and mind do', the highest frequency code was the mention of brain scanning technologies (42.2\%) such as 
fMRI, PET (Positron Emission Computed Tomography), and EEG (Electroencephalogram) (Racine, 2005). Second most frequent was brain wave research such as brain cell stimulation (39.4\%). However, the frequency of near-death experiences (4.6\%) and animal brain research (13.8\%) was relatively low. Both Chinese and Japanese newspapers had similar proportions individually as the overall frequencies. It can be seen from Table 6 that brain scans and brain waves account for the largest proportion of this theme, with the Japanese articles in particular preferring to mention these topics.

Furthermore, in the sections on sociological and practical implications the frequency of codes were $128(16.5 \%)$ and $122(15.7 \%)$, respectively. In the former theme, the most frequent coder was AI (48.4\%) such as its uses in the treatment of Parkinson's disease. Meanwhile, efficiency improvement (45.9\%) such as how to create better life for the disabled takes up the greatest quantity. There is an adverse data indication between China and Japan. In the Chinese newspapers, information about the practical implication occupies more focus of the articles, at $63.9 \%$, while Japanese articles place more concentration on sociological implications, at $62.5 \%$.

As previously mentioned there are three tendencies in articles on neuroscientific technologies: neuro-essentialism, neuro-realism, and neuro-policy. Therefore, in discussion of the themes of philosophical or existential implications, the results will be shown based on these trends. Within the sample of this dissertation, neuro-essentialism is often mentioned in philosophical implications, especially in the Chinese materials in which 97\% support neuro-realism, with discussion such as "With the help of brain wave technology, we can describe a complete map for human brain activity" (01). However, around 57\% of the sampled Japanese newspaper reporting conveys information in a neuro-essentialist manner: "The human brain is still one of the biggest secrets of science" (005).

\subsection{Focus Group Findings}

As the research questions of this study are about the public perception of the media representation of neuroscience, the focus group transcripts were coded in a frame of media newspapers, which can be seen in Table 5. Each transcript was coded by a unique number, those from the Chinese focus group had numbers beginning with $\mathrm{C}$ and those from the Japanese group all began with J, allowing each participant a unique identification number (Table 7).

\subsubsection{Chinese Perception of Neuroscience}

1) CA-Theme: What the brain and mind are

In terms of the global theme "what the brain and mind are" the common impression of neuroscience of the participants involved discussion of brain diseases: "I rarely hear anything about it. However, the information on brain disease is more familiar to me, especially cerebral infarction" (C3). There was also mention of how the media representation influenced them: "Actually, information about brain healthcare, such as protection against cerebral apoplexy, is a 
Table 6. Frequency/Percentage of five themes in newspaper coverage of neuroscience (Underlined is the largest number; Bold is the least number).

\begin{tabular}{|c|c|c|c|c|}
\hline Themes & Coders & Total (\%) & China (\%) & Japan (\%) \\
\hline \multirow{6}{*}{$\begin{array}{l}\text { What are } \\
\text { brain and mind }\end{array}$} & Brain tumor & $2(0.7)$ & $2(1.1)$ & $0(0)$ \\
\hline & Cerebral injury & $\underline{58(26.1)}$ & $\underline{42(23)}$ & $\underline{16(40)}$ \\
\hline & Encephala trophy & $42(18.9)$ & $40(22)$ & $2(5)$ \\
\hline & Cerebral apoplexy & $46(21.0)$ & $40(22)$ & $6(15)$ \\
\hline & Brain health care & $52(23.4)$ & $40(22)$ & $12(30)$ \\
\hline & Traditional Chinese medicine & $4(2)$ & $4(2.2)$ & $0(0)$ \\
\hline \multirow{3}{*}{ Total } & Brain death & $18(8)$ & $14(8)$ & $4(10)$ \\
\hline & & $222(28.6)$ & $182(41.4)$ & $40(11.9)$ \\
\hline & Brain wave research & $86(39)$ & $32(35)$ & $\underline{54(42)}$ \\
\hline \multirow{3}{*}{$\begin{array}{l}\text { What brain } \\
\text { and mind do }\end{array}$} & Near-death experience & $10(5)$ & $8(9)$ & $2(2)$ \\
\hline & Animals' brain researches & $30(14)$ & $14(15)$ & $16(13)$ \\
\hline & Brain scan (i.e. fMRI) & $\underline{92(42)}$ & $\underline{38(41)}$ & $\underline{54(42)}$ \\
\hline \multirow[t]{2}{*}{ Total } & & $218(28.1)$ & $92(20.9)$ & $126(37.5)$ \\
\hline & $\begin{array}{l}\text { Self-consciousness } \\
\text { based on the brain activities }\end{array}$ & $\underline{46(53)}$ & $\underline{22(55)}$ & $24(52)$ \\
\hline \multirow{3}{*}{$\begin{array}{l}\text { Philosophical or } \\
\text { existential } \\
\text { implications }\end{array}$} & $\begin{array}{l}\text { Doubt about the } \\
\text { consciousness after death }\end{array}$ & $12(14)$ & $8(20)$ & $4(8.7)$ \\
\hline & Doubt about the soul & $12(14)$ & $8(20)$ & $4(8.7)$ \\
\hline & $\begin{array}{l}\text { Subjective experience (i.e. sprit is } \\
\text { out of body experience) }\end{array}$ & $14(16)$ & $2(5)$ & $12(26.1)$ \\
\hline \multirow{3}{*}{ Total } & Discussion about the after death world & $2(2)$ & $0(0)$ & $2(4.3)$ \\
\hline & & $86(11.1)$ & $40(9.1)$ & $46(13.7)$ \\
\hline & $\mathrm{AI}$ & $62(48)$ & $14(29.2)$ & $48(60)$ \\
\hline \multirow{4}{*}{$\begin{array}{l}\text { Sociological } \\
\text { implications }\end{array}$} & $\begin{array}{c}\text { Smart home } \\
\text { (i.e. Intelligent home system) }\end{array}$ & $10(7.8)$ & $4(8.3)$ & $6(7.5)$ \\
\hline & Military & $6(4.7)$ & $6(12.5)$ & $0(0)$ \\
\hline & Driverless car & $6(4.7)$ & $6(12.5)$ & $0(0)$ \\
\hline & New media (i.e. virtual reality) & $20(15.6)$ & $8(16.7)$ & $12(15)$ \\
\hline \multirow{3}{*}{ Total } & Medical care & $\underline{24(18.8)}$ & $\underline{10(20.8)}$ & $\underline{14(17.5)}$ \\
\hline & & $128(16.5)$ & $48(10.9)$ & $80(23.8)$ \\
\hline & Improvement of first aid & $44(36)$ & $\underline{36(46.2)}$ & $8(18.2)$ \\
\hline \multirow{2}{*}{$\begin{array}{l}\text { Practical } \\
\text { implications }\end{array}$} & $\begin{array}{l}\text { Efficiency improvement } \\
\text { (i.e. the disabled) }\end{array}$ & $\underline{56(45)}$ & $24(28.2)$ & $\underline{32(72.7)}$ \\
\hline & $\begin{array}{l}\text { Sleeping insurance (i.e. the sleeping } \\
\text { time of night shift workers) }\end{array}$ & $22(18)$ & $18(23.1)$ & $4(9.1)$ \\
\hline \multirow[t]{2}{*}{ Total } & & $122(15.7)$ & $78(17.8)$ & $44(13.1)$ \\
\hline & & 776 & 440 & 336 \\
\hline
\end{tabular}


Table 7. The focus group results of Chinese participants.

\begin{tabular}{ccccccc}
\hline & $\%$ & $\begin{array}{c}\text { \% Coded } \\
\text { proportion }\end{array}$ & $\begin{array}{c}\text { \% Coded } \\
\text { proportion }\end{array}$ & $\begin{array}{c}\text { \% Coded } \\
\text { proportion }\end{array}$ & $\begin{array}{c}\text { \% Coded } \\
\text { proportion }\end{array}$ & $\begin{array}{c}\text { \% Coded } \\
\text { proportion }\end{array}$ \\
\cline { 2 - 7 } & Total & $\begin{array}{c}\text { What the brain } \\
\text { and mind are }\end{array}$ & $\begin{array}{c}\text { What brain } \\
\text { and mind do }\end{array}$ & $\begin{array}{c}\text { Philosophical or } \\
\text { existential } \\
\text { implications }\end{array}$ & $\begin{array}{c}\text { Sociological } \\
\text { implications }\end{array}$ & $\begin{array}{c}\text { Practical } \\
\text { implications }\end{array}$ \\
\hline Sila C1 & $12 \%$ & 37 & 34 & 12 & 7 & 10 \\
Bu C2 & $7 \%$ & 2 & 14 & 30 & 27 & 27 \\
Zhou C3 & $16 \%$ & 26 & 7 & 33 & 20 & 14 \\
Liao C4 & $14 \%$ & 21 & 12 & 30 & 23 & 14 \\
Hu C5 & $17 \%$ & 30 & 11 & 32 & 9 & 18 \\
Wang C6 & 21\% & 12 & 14 & 13 & 20 & 41 \\
Tao C7 & $13 \%$ & 4 & 30 & 36 & 15 & 15 \\
& $\%$ of participant speech which is counted by words, excluding facilitator & \\
\hline
\end{tabular}

common topic for me" (C5). Almost half of the participants noted the main information they had received about neuroscience is about medical research of the brain, with improvement of medical technologies related to the brain and the knowledge of brain healthcare being of particular focus.

Furthermore, media information was mentioned, with newspaper reports on neuroscience being the group's main source of connection to this scientific area: "The Chinese media seems to prefer this kind of report" (C6). Moreover, the form of media communication would affect the credibility of neuroscientific information for the participants: "I would notice the information from news media whether it was online or offline. However, for me, the more influential media are documentaries and books" (C4). The discussion about the credibility of neuroscience newspaper would be further demonstrated in the themes of philosophical or existential implications.

2) CA-Theme: What brain and mind do

On the second global theme of discussion, what the brain and mind do,the participants in the Chinese focus group talked about brain scanning technology and brain wave research which were used to help the public understand brain activity. Interestingly, there were two opposing points on brain waves. Some participants thought they were just a way to visualize how the brain or mind works:

"There was an American scholar who tested a monk's brain through scanning technology. The results of this test were recorded by brain waves. The researcher found the monk was one of the happiest people in this world." (C3)

While other participants supported that brain waves were the essence of our brain and mind. In other words, they generated feelings, minds, and emotions which $\mathrm{C} 2$ held to be experiences which are "all the results of brain waves".

3) CA-Theme: Philosophical or existential implications 
There were two opinions among the participants in the Chinese focus group when they discussed philosophical or existential implications of neuroscience. Some claimed the brain and mind were independent, similar to the concept of neuro-essentialism reasoned by subjective experiences:

"I experience things such as predictive dreams. After having these strange dreams, I will look up the studies of both Freud and the Duke of Zhou to explain them. There are a lot of secrets of our brain and mind" (C3)

"I have subjective experiences... such as dreams about my past life. Therefore, I believe our brain and mind are separated" (C1)

The other participants' opinions of philosophical interpretation were more likely to support neuro-realism, considering the brain and mind to be integrated. In particular, they believed the brain and mind can be explored by neuroscientific technologies:" I believe the knowledge and information in our brains can be quantified as data. Our soul is also the production of this data." (C6).

Here, the participants mentioned the conflict between neuroscience newspaper information and their own values, showing there was a communicative gap between the media representation and the public: "The newspapers never support things which cannot be explained." (C5). In addition to this, the participants worried about the utilitarian nature of the Chinese newspaper, particularly the controlling power of the government, stating: "Even though the mainstream media gives an explanation, they always base their answer on materialism, which is greatly one-sided information" (C7) and "the newspaper in China has a political purpose" (C6).

4) CA-Theme: Sociological implications

In response to sociological implications, most participants mentioned the development of AI and medical applications based on the brains of human beings, including discussion of Chess AI and medical robots: "I have learnt to implement neural networks using machine learning. The tools which we used to establish the network was Google Alpha Go. This is the implication of the neural network method" (C6). Furthermore, they talked about the medical areas of neuroscience:"Nowadays, medical robotics is very developed, designed according to our human brains" (C1).

5) CA-Theme: Practical implications

As for the theme of practical implications, the participants mentioned the importance of sleeping improvement based on neuroscience researches:" I would relate neuroscience to sleeping habits. Because China develops too fast, there are a lot of people who have problems sleeping. Therefore, many neuroscientific research results are geared towards solving this problem" (C3). The second highest frequency of the neuroscientific practical application was about the progress of first-aid.

\subsubsection{Japanese Perception of Neuroscience}

The Japanese focus group also suggested their first impression of neuroscience 
newspaper reports was focused on medical issues. However, they all mentioned the information about neuroscience was mainly about brain tumors: "I noticed neuroscience information is usually about brain tumors” (J2) (Table 8).

As for the topic of brain activity, almost all participants mentioned the newspaper reporting of brain wave studies: "There are a lot of newspapers concentrate on the development of brain wave research" (J3).

When asked about their impression of neuroscience, the majority of Japanese participants were familiar with AI technology: "For me, the newspapers seem to prefer to report on the neuroscience information of AI, such as wearable devices" (J1).

Generally, on the theme of philosophical and existential implications of neuroscience, the Japanese participants supported neuro-essentialism: "There is no clear and straightforward explanation of some issues such as when the sprit frees itself from the body" (J1).

There was distinction between the two focus groups on the themes of sociological and practical implications of neuroscience. The first reaction of the Japanese participants to this question was about neuroscientific knowledge related to life and business applications: "Neuroscience is related to many areas, especially management and finance. I believe neuroscience even lays the foundation of many scientific areas' (J3). In addition, they talked about the application of neuroscientific knowledge in the sports field, and its effect on the efficiency of athletes: "Sports management is closely related to neuroscience" (J4).

\subsection{Conclusion: Communicative Content and Form of Neuroscience}

The results of media content analyses and focus groups indicate that there are notable distinctions about the media representation of neuroscience between China and Japan. All the differences of public perception of neuroscience between China and Japan can be divided into two sections-communicative content and form of neuroscience.

Table 8. The focus group results of Japanese participants.

\begin{tabular}{|c|c|c|c|c|c|c|}
\hline & $\%$ & $\begin{array}{l}\% \text { Coded } \\
\text { proportion }\end{array}$ & $\begin{array}{l}\% \text { Coded } \\
\text { proportion }\end{array}$ & $\begin{array}{l}\% \text { Coded } \\
\text { proportion }\end{array}$ & $\begin{array}{l}\% \text { Coded } \\
\text { proportion }\end{array}$ & $\begin{array}{l}\% \text { Coded } \\
\text { proportion }\end{array}$ \\
\hline JP & Total & $\begin{array}{l}\text { What the brain } \\
\text { and mind are }\end{array}$ & $\begin{array}{l}\text { What brain } \\
\text { and mind do }\end{array}$ & $\begin{array}{c}\text { Philosophical } \\
\text { or existential } \\
\text { implications }\end{array}$ & $\begin{array}{l}\text { Sociological } \\
\text { implications }\end{array}$ & $\begin{array}{c}\text { Practical } \\
\text { implications }\end{array}$ \\
\hline Leo J1 & $10 \%$ & 7 & 27 & 20 & 19 & 27 \\
\hline Yamamoto J2 & $7 \%$ & 13 & 30 & 15 & 2 & 40 \\
\hline Natsuki J3 & $16 \%$ & 26 & 7 & 33 & 15 & 19 \\
\hline Mioko J4 & $14 \%$ & 40 & 14 & 23 & 11 & 12 \\
\hline
\end{tabular}




\subsubsection{Communicative Content}

More detailed, in the themes of the nature of brain or mind (what is brain and mind, and what brain and mind does), sociological implications and practical implications, it can be obviously deducted that the Chinese public lays more emphasis on medical field of neuroscience. The quotation sources of Chinese newspaper are supported by medical workers and patients. Even Chinese articles on the newspaper are more likely to report the medical information of neuroscience, such as brain health care and cerebral apoplexy. Furthermore, as to the neuroscientific implications, Chinese media coverage also lays more emphasis on the improvement of first aid than Japan.

The results of the Chinese focus group also support this argument. The participants said in the CA: "the information about the brain health care is a common topic for me, such as the prevention of cerebral apoplexy." (C3) On the other hand, Japanese newspaper coverage of neuroscience mainly cites the evidence and the data support from scientists. The brain scanning technology is the core content in Japanese articles. It is worth mentioning that the future potential of sociology implication of neuroscience such as AI is another important research area in Japanese media coverage. Overall, the Japanese public perception of neuroscience mainly concentrates on the economic value and daily life. In the theme of philosophical or existential implications, the Chinese public perception of neuroscience tends to be more neuro-realistic than Japanese. Especially, the Chinese newspaper articles have presented more description of neuroscience.

\subsubsection{Communicative Forms}

When it comes to the communicative forms of neuroscience, the Chinese participants in the focus group commented that the articles about neuroscience on Chinese newspaper lacked credibility among the public, and especially the top-down media coverage of neuroscience had caused Chinese individuals' confidence crisis to the government. The participants also talked about the utilitarianism in the newspaper, which is another reason for their distrust.

Japanese scientists lack the communication between the public. More importantly, they have no conscious to use the simple neuroscience language in their scientific results. Therefore, in the Japanese focus group, the participants reflect that there is an information gap between them and the scientists. It is really hard for them to fully understand what the scientists' meaning in the newspapers. And this situation would lead to the indifference of the Japanese individual's attitude to the development of neuroscience.

\section{Conclusions}

The results of media content analyses and focus groups indicate that there are notable distinctions about the media representation of neuroscience between China and Japan. All the differences of public perception of neuroscience between China and Japan can be divided into two sections-communicative content and form of neuroscience. The comparison figure of the five themes between China and Japan can be seen in Figure 2. 


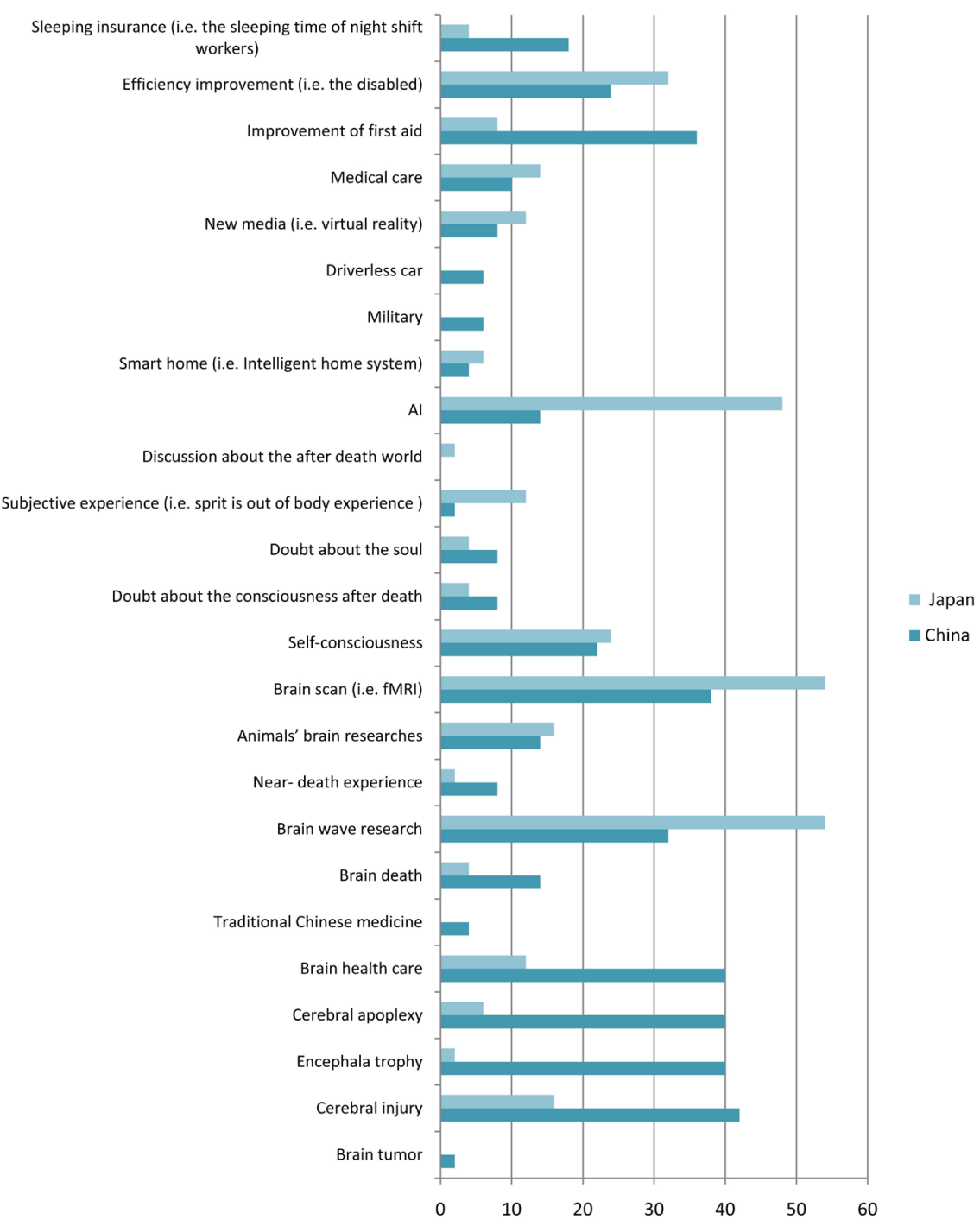

Figure 2. The comparison figure of the five themes between China and Japan.

\subsection{Communicative Content}

More detailed, in the themes of the nature of brain or mind (what is brain and mind, and what brain and mind does), sociological implications and practical implications, it can be obviously deducted that the Chinese public lays more emphasis on medical field of neuroscience. The quotation sources of Chinese newspaper are supported by medical workers and patients. Even Chinese articles on the newspaper are more likely to report the medical information of neuroscience, such as brain health care and cerebral apoplexy. Furthermore, as to the neuroscientific implications, Chinese media coverage also lays more emphasis on the improvement of first aid than Japan.

The results of the Chinese focus group also support this argument. The participants said in the CA: "the information about the brain health care is a common topic for me, such as the prevention of cerebral apoplexy." (C3) On the other hand, Japanese newspaper coverage of neuroscience mainly cites the evi- 
dence and the data support from scientists. The brain scanning technology is the core content in Japanese articles. It is worth mentioning that the future potential of sociology implication of neuroscience such as AI is another important research area in Japanese media coverage. Overall, the Japanese public perception of neuroscience mainly concentrates on the economic value and daily life. In the theme of philosophical or existential implications, the Chinese public perception of neuroscience tends to be more neuro-realistic than Japanese. Especially, the Chinese newspaper articles have presented more description of neuroscience.

\subsection{Communicative Forms}

When it comes to the communicative forms of neuroscience, the Chinese participants in the focus group commented that the articles about neuroscience on Chinese newspaper lacked credibility among the public, and especially the top-down media coverage of neuroscience had caused Chinese individuals' confidence crisis to the government. The participants also talked about the utilitarianism in the newspaper, which is another reason for their distrust.

Japanese scientists lack the communication between the public. More importantly, they have no conscious to use the simple neuroscience language in their scientific results. Therefore, in the Japanese focus group, the participants reflect that there is an information gap between them and the scientists. It is really hard for them to fully understand what the scientists' meaning in the newspapers. And this situation would lead to the indifference of the Japanese individual's attitude to the development of neuroscience.

\section{Conflicts of Interest}

The author declares no conflicts of interest regarding the publication of this paper.

\section{References}

[1] Devillers-Thiéry, A., Giraudat, J., Bentaboulet, M. and Changeux, J.P. (1983) Complete mRNA Coding Sequence of the Acetylcholine Binding $\alpha$-Subunit of Torpedo Marmorata Acetylcholine Receptor: A Model for the Transmembrane Organization of the Polypeptide Chain. Proceedings of the National Academy of Sciences of the USA, 80, 2067-2071. https://doi.org/10.1073/pnas.80.7.2067

[2] Churchland, P.S. (1989) Neurophilosophy: Toward a Unified Science of the MindBrain. MIT Press.

[3] Young, L. and Saxe, R. (2008) The Neural Basis of Belief Encoding and Integration in Moral Judgment. Neuroimage, 40, 1912-1920. https://doi.org/10.1016/j.neuroimage.2008.01.057

[4] Racine, E., Waldman, S., Rosenberg, J. and Illes, J. (2010) Contemporary Neuroscience in the Media. Social Science \& Medicine, 71, 725-733. https://doi.org/10.1016/j.socscimed.2010.05.017

[5] Racine, E., Bar-Ilan, O. and Illes, J. (2006) Brain Imaging: A Decade of Coverage in the Print Media. Science Communication, 28, 122-143. https://doi.org/10.1177/1075547006291990 
[6] van Atteveldt, N.M., van Aalderen-Smeets, S.I., Jacobi, C. and Ruigrok, N. (2014) Media Reporting of Neuroscience Depends on Timing, Topic and Newspaper Type. PloS ONE, 9, e104780. https://doi.org/10.1371/journal.pone.0104780

[7] Vrecko, S. (2010) Neuroscience, Power and Culture: An Introduction.

[8] Grabowski, M., Ed. (2014) Neuroscience and Media: New Understandings and Representations (Vol. 70). Routledge. https://doi.org/10.4324/9781315749235

[9] Gay, V.P., Ed. (2009) Neuroscience and Religion: Brain, Mind, Self, and Soul. Lexington Books.

[10] Slingerland, E. (2008) What Science Offers the Humanities: Integrating Body and Culture. Cambridge University Press. https://doi.org/10.1017/CBO9780511841163

[11] Putnam, H. (1973) Reductionism and the Nature of Psychology. Cognition, 2, 131-146. https://doi.org/10.1016/0010-0277(72)90033-9

[12] Racine, E., Bar-Ilan, O. and Illes, J. (2005) fMRI in the Public Eye. Nature Reviews. Neuroscience, 6, 159. https://doi.org/10.1038/nrn1609

[13] Holman, K. (2011) Coverage of Neuroscience in the Popular Media. The New Psychobabble, Brain Blogger.

[14] Giridhardas, A. (2008) India's Novel Use of Brain Scans in Courts Is Debated. The New York Times.

[15] Stokes, M. (2013) There's a Lot More to Neuroscience than Media "Neuromania". The Guardian.

[16] Beck, D.M. (2010) The Appeal of the Brain in the Popular Press. Perspectives on Psychological Science, 5, 762-766. https://doi.org/10.1177/1745691610388779

[17] Lü, L. (2009) The Value of the Use of Biotechnology: Public Views in China and Europe. Public Understanding of Science, 18, 481-492. https://doi.org/10.1177/0963662507082892

[18] Ren, J., Peters, H.P., Allgaier, J. and Lo, Y.Y. (2014) Similar Challenges but Different Responses: Media Coverage of Measles Vaccination in the UK and China. Public Understanding of Science, 23, 366-375. https://doi.org/10.1177/0963662512445012

[19] Raza, G., Kumar, P.V.S. and Singh, S. (2011) Public Understanding of Environment and Bioenergy Resources. Journal of Science Communication, 10, A03. https://doi.org/10.22323/2.10030203

[20] Kawamoto, S., Nakayama, M. and Saijo, M. (2013) A Survey of Scientific Literacy to Provide a Foundation for Designing Science Communication in Japan. Public Understanding of Science, 22, 674-690. https://doi.org/10.1177/0963662511418893

[21] Zhang, J.Y. (2015) The "Credibility Paradox" in China's Science Communication: Views from Scientific Practitioners. Public Understanding of Science, 24, 913-927. https://doi.org/10.1177/0963662515598249

[22] Jia, H. and Liu, L. (2014) Unbalanced Progress: The Hard Road from Science Popularisation to Public Engagement with Science in China. Public Understanding of Science, 23, 32-37. https://doi.org/10.1177/0963662513476404

[23] Koizumi, A., Morita, Y. and Kawamoto, S. (2013) Science Communication: Reward Research Outreach in Japan. Nature, 500, 29. https://doi.org/10.1038/500029a

[24] Kornhauser, D. (2015) News Center. Okinawa Institute of Science and Technology Graduate University.

https://www.oist.jp/news-center/news/2015/3/24/transforming-japanese-science-co mmunication

[25] Bauer, M.W., Kohring, M., Allansdottir, A. and Gutteling, J. (2001) The Dramatisa- 
tion of Biotechnology in Elite Mass Media.

[26] Sue, R. and Ylva, F. (1999) The Marketing and Public Relations Handbook for Museums, Galleries and Heritage Attractions.

[27] Berelson, B. (1952) Content Analysis in Communications Research.

[28] Bauer, M.W. and Gaskell, G. (2000) Qualitative Researching with Text, Image and Sound: A Practical Handbook for Social Research. Sage, Thousand Oaks. https://doi.org/10.4135/9781849209731

[29] Chen Krippendorff, K. (2004) Content Analysis: An Introduction to Its Methodology. Sage, Thousand Oaks.

[30] Chen, Y. (2000) The Application of Semiotics to Mass Communication. International Press, 4, 46-50.

[31] Tennant, C. (2012) On the Threshold: A Social Psychological Study of Different Standpoints in the Climate Change Debate. Doctoral Dissertation, The London School of Economics and Political Science.

[32] Bauer, M.W. and Gaskell, G. (1999) Towards a Paradigm for Research on Social Representations. Journal for the Theory of Social Behaviour, 29, 163-186. https://doi.org/10.1111/1468-5914.00096 